Article

\title{
Oxidation Behavior and Structural Transformation of (CrTaTiVZr)N Coatings
}

\author{
Zue-Chin Chang * and Jun-Yang Liang \\ Department of Mechanical Engineering, National Chin-Yi University of Technology, Taichung 41170, Taiwan; \\ a81921123@gmail.com \\ * Correspondence: chang@ncut.edu.tw; Tel.: +886-4-2392-4505
}

Received: 24 February 2020; Accepted: 20 April 2020; Published: 22 April 2020

\begin{abstract}
CrTaTiVZr)N coatings were prepared on Si substrates through the reactive magnetron sputtering system to investigate the oxidation behaviors and structural evolution of the coatings at different annealing temperatures in air. The (CrTaTiVZr) N coating had a face-centered cubic structure with an oxidation temperature of up to $300^{\circ} \mathrm{C}$, but its surface changed into the amorphous oxide phase and then into the rutile $\mathrm{TiO}_{2}$ phase when the annealing temperature was increased to $500^{\circ} \mathrm{C}$. The rutile $\mathrm{TiO}_{2}$ phase continued to grow, and an additional solid solution phase of body-centered tetragonal I41/amd was formed at annealing temperatures beyond $600{ }^{\circ} \mathrm{C}$. The high annealing temperature promoted the oxidation to progress along the thickness direction and synergistically developed the porosity. As a result, the hardness and the electrical performance of the coating deteriorated. The hardness decreased from $34.30 \mathrm{GPa}$ to $1.52 \mathrm{GPa}$, and the electrical resistivity increased from $142 \mu \Omega \cdot \mathrm{cm}$ to $17.5 \Omega \cdot \mathrm{cm}$.
\end{abstract}

Keywords: high entropy; hard coating; oxidation resistance

\section{Introduction}

The use of high-entropy alloys (HEAs) comprising at least five principal elements with concentrations between 5 at. $\%$ and 35 at. $\%$ has good potential in the design of new metallic multicomponent alloys [1-3]. This specific composition design is compatible with the four core factors of HEAs, namely, high entropy, sluggish diffusion, lattice distortion, and cocktail effect $[1,2]$. The high mixing entropy enhances the mutual solubility among elements and reduces the tendency of phase separation into ordered phases or intermetallic compounds. The sluggish diffusion decreases the diffusion rate and results in the formation of nanocrystalline or even amorphous structures. The lattice distortion hinders the dislocation motion and results in a significantly strengthened solid solution. Finally, cocktail effects cause a composite effect in HEAs. The interaction and influence of alloy components are reflected in the alloy properties and produce additional effects. With proper alloy designs, the alloy components have shown properties that outperform traditional materials, such as high hardness and superior resistance to temper softening, wear, oxidation, and corrosion.

On the basis of the development of HEAs, HEA films are frequently investigated because of their mechanical and thermal properties. Many researchers have prepared HEA films by using various methods, such as magnetron sputtering [4-12], laser cladding [13-15], electrochemical deposition [16], arc thermal spraying [17], cold spraying [18], electron beam evaporation deposition [19], and plasma cladding [20]. At present, laser cladding and magnetron sputtering are commonly used by researchers to obtain films with excellent physical properties. The laser cladding technology is used to form coatings by melting metal powder by using high-power and high-speed lasers. This strategy provides many unparalleled advantages in forming refractory HEAs. The rapid solidification velocity enables nonequilibrium solute trapping and avoids component segregation. The coating combined with the 
metallurgy matrix remarkably improves the bonding strength. However, cracks and pores easily occur during laser cladding [12]. Sputtering deposition occurs due to the ion bombardment on targets by using plasma and knocking the atoms off the target surface. The high kinetic energy of the knockout target atoms allows the formation of compact and smooth films. However, sputtered films produce limited film thickness and poor bonding strength between the film and the substrate. The advantage of the sputtering method is the deposition of HEA nitride (HEAN) films. HEAN films are easily synthesized due to the easy incorporation of the nitrogen during deposition. This feature provides an effective way of exploring the HEAN system.

Additional applications have been expanded recently by producing HEANs in the form of thin films, such as (AlCoCrNi)N [4], (TiZrHfNiCuCo)N [5], (CrTaTiVZr)N [6,7], (TiZrNbAlYCr)N [8], (AlCrNbSiTiV)N [9], (FeCoNiCrCuAl 0.5$) \mathrm{N}$ [10], (FeCoNiCuVZrAl)N [11], and (TiVCrZrNbMoHfTaWAlSi)N [12]. Almost all HEAN coatings consist of a single face-centered cubic (FCC) solid solution structure. Their mechanical properties strongly depend on the process parameters and constituent elements. Our previous research has investigated the structural evolution and the mechanical and the electro-optical properties of (CrTaTiVZr) N coatings [7]. The target constituents are all refractory, and strong nitride-forming elements are designed to deposit strong nitride coatings. In the past years, sputtered ternary (CrTiV)N coatings have exhibited a hardness of $18.74 \mathrm{GPa}$ [21]. Large and heavy Ta and $\mathrm{Zr}$ atoms are incorporated to improve microstructure and mechanical properties, suppress grain growth, increase the energy of sputtered and backscattered atoms reaching the substrate, densify the coating structure, and enhance physical performance [22]. (CrTaTiVZr) N coatings are characterized by hardness and electrical conductivity of $36.4 \mathrm{GPa}$ and $7633 \mathrm{~S} \cdot \mathrm{cm}^{-1}$, respectively, with light reflectivity of $74 \%$ near $2000 \mathrm{~nm}$. These findings indicate the competitiveness of these coatings in coating applications. Compared with some high-entropy nitrides with non-nitride-forming elements, such as $\mathrm{Ni}, \mathrm{Cu}$, and $\mathrm{Fe},(\mathrm{CrTaTiVZr}) \mathrm{N}$ coatings have better mechanical properties. On the other hand, AlN and $\mathrm{Si}_{3} \mathrm{~N}_{4}$ are electrically insulating materials, and their incorporation into HEANs results in high electrical resistivity and low infrared reflectivity. These features make their applicability in microelectronic and optical fields questionable. By contrast, (CrTaTiVZr)N coatings exhibit satisfactory electro-optical performance. However, a detailed study on their oxidation resistance and structural changes during the thermal process in air is lacking. The oxidation resistance of coatings has become an important issue because of their widespread application. For instance, infrared-reflective coatings on solar-selective applications are necessary for the concentration of sunlight on heat-collecting elements. However, the high temperature provided by sunlight causes coating instability, resulting in loss in reflectivity. Ideal durable infrared-reflective coatings require high infrared reflectivity and durability in oxidation resistance at high temperatures. Developing high-temperature air-stable solar-selective coatings is urgently needed. In another example, under some machining conditions, the temperature at contact points between the tool and the workpiece becomes high. Machining without the application of coolants has been a common trend in the industry to reduce health and environmental effects but leads to excessive heat. Thus, the oxidation behavior of protective coatings under high temperature in air is becoming critical. Therefore, this study attempted to grow (CrTaTiVZr)N coatings for applications with high temperature in air. The mechanical and electrical properties after annealing at different temperatures in air were evaluated. The crystal phase evolutions and microstructure developments were also investigated.

\section{Experimental}

(CrTaTiVZr)N coatings were deposited on $p$-Si (100) wafers and fused quartz via the DC magnetron sputtering system by using equimolar CrTaTiVZr targets with a diameter of $75 \mathrm{~mm}$. All elements in the target had the same molar ratios. Prior to deposition, the $p$-Si (100) wafers were cleaned in an ultrasonic bath and rinsed thoroughly with ethanol and distilled water. These wafers were then placed in the vacuum system. The distance from the target to the substrate was $90 \mathrm{~mm}$, and the deposition angle was $60^{\circ}$ relative to the substrate. The substrate stage was rotated at $5 \mathrm{rpm}$ to obtain the quality and 
thickness of a homogeneous film. The coating thickness was set to approximately $1 \mu \mathrm{m}$. The sputtering system consisted of a stainless-steel vacuum chamber and a rotary turbo pump, which provided an ultimate vacuum of $7 \times 10^{-6}$ Torr before the gases were introduced. (CrTaTiVZr) N coatings were deposited under an $\mathrm{Ar}+\mathrm{N}_{2}$ mixed atmosphere at a DC power and working pressure of $400 \mathrm{~W}$ and $6.67 \times 10^{-1} \mathrm{~Pa}$, respectively. During deposition, the Ar and the $\mathrm{N}_{2}$ flow rates were 40 and $10 \mathrm{sccm}$, respectively. The substrate was not subjected to external substrate bias and heating. The as-deposited nitride coatings were annealed at different temperatures $\left(300-700{ }^{\circ} \mathrm{C}\right)$ for $2 \mathrm{~h}$ in air by using a furnace to determine their oxidation resistance.

The chemical compositions of (CrTaTiVZr) N coatings were determined via field-emission electron probe microanalyses (FE-EPMA, JEOL JXA-8800 M, JEOL Ltd., Tokyo, Japan), and at least three tests were performed on each sample. The crystal structures were analyzed using a glancing-incidence $\left(1^{\circ}\right)$ X-ray diffractometer (XRD, BRUKER D8 Discover, Bruker, Billerica, MA, USA) with $\mathrm{Cu} \mathrm{K} \alpha$ radiation at a scanning speed of $1^{\circ} \cdot \mathrm{min}^{-1}$. The scanning step and range were $0.02^{\circ}$ and $10^{\circ}-80^{\circ}$, respectively. Morphological studies were carried out using a field-emission scanning electron microscope (SEM, JEOL JSM-6700F, JEOL Ltd., Tokyo, Japan). The microstructural examinations were conducted using an analytic transmission electron microscope (TEM, FEI E.O. TecnaiF20, Tecnai F20 G2, EFI, Hillsboro, OR, USA). The hardness and elastic modulus of coatings were measured using the TriboLab nanoindenter (Hysitron Inc., Minneapolis, MN, USA) with a Berkovich diamond indenter tip (tip radius of approximately $50 \mathrm{~nm}$ ). During the tests, a maximum applied load of $5000 \mu \mathrm{N}$ was set. At least five tests were performed on each sample. The electrical resistivity of coatings was measured using a four-point probe system.

\section{Results and Discussion}

The coating stability at elevated temperature in air (ambient environment in the majority of applications) is a crucial factor. Figure 1 demonstrates the FE-EPMA results of (CrTaTiVZr)N coatings after annealing at different temperatures in air. The $\mathrm{N}$ content of coatings significantly decreased, whereas the $\mathrm{O}$ content increased with increased annealing temperatures above $300{ }^{\circ} \mathrm{C}$. After annealing at $600{ }^{\circ} \mathrm{C}$, the $\mathrm{O}$ content reached 61.0 at. $\%$, whereas $\mathrm{N}$ was undetected in the coating. The absence of $\mathrm{N}$ implied that complete oxidation occurred. The extremely larger enthalpies in the formation of metal oxides relative to those of metal nitrides cause the rapid oxidation [23,24]. Notably, the constituent metal content in the coating was almost the same after annealing. Except $\mathrm{V}_{2} \mathrm{O}_{5}$, which had a relatively low melting point $\left(690^{\circ} \mathrm{C}\right.$ ), the oxides of the target constituents had high melting points (over $700^{\circ} \mathrm{C}$ ). The $\mathrm{V}_{2} \mathrm{O}_{5}$ phase formed during annealing may cause a slight loss in the $\mathrm{V}$ content. In other words, no $\mathrm{V}_{2} \mathrm{O}_{5}$ crystal phase was formed in this study.

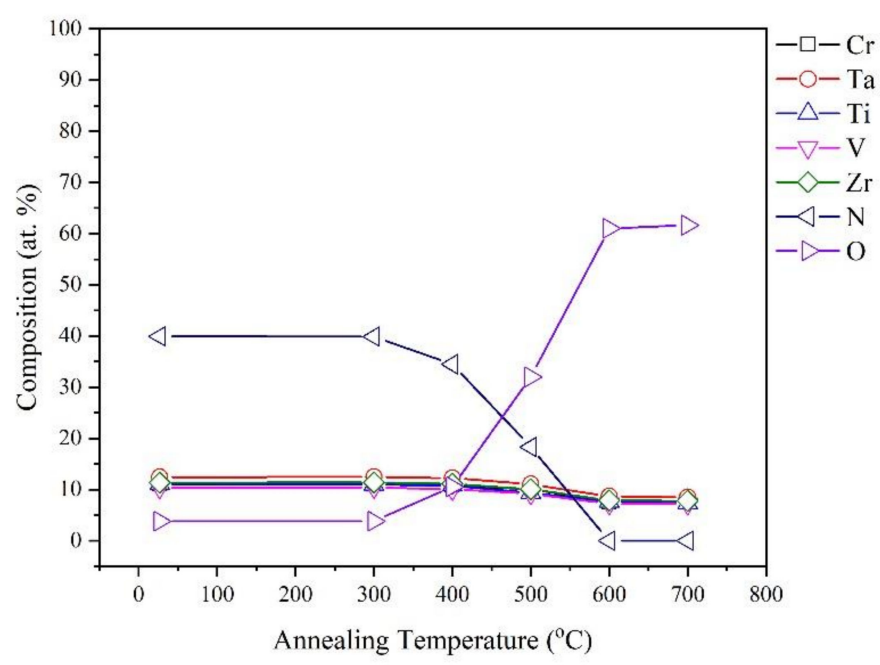

Figure 1. FE-EPMA results of (CrTaTiVZr)N after annealing at different temperatures in air. 
Figure 2 shows the XRD patterns of (CrTaTiVZr)N coatings after annealing at different temperatures in air. At $300{ }^{\circ} \mathrm{C}$, no phase transformation was detected. The FCC peaks were sustained at $400^{\circ} \mathrm{C}$, but the FCC (111) peak weakened. The FCC peaks disappeared due to the increased annealing temperature $\left(500{ }^{\circ} \mathrm{C}\right.$ ), and the rutile $\mathrm{TiO}_{2}$ phase began to form. The increase in annealing temperature to $600{ }^{\circ} \mathrm{C}$ caused the appearance of an additional tetragonal phase. The relative integrated intensity of oxide phases increased sharply at $700{ }^{\circ} \mathrm{C}$. This result indicated that rapid oxidation occurred at $500{ }^{\circ} \mathrm{C}$ with the formation of a nonprotective oxide layer. The initial crystalline $\mathrm{TiO}_{2}$ phase is usually a metastable anatase due to the faster recrystallization caused by its lower surface free energy compared with that of a rutile phase. The reported crystallization onset temperatures in the anatase phase often appear at around $300{ }^{\circ} \mathrm{C}$. Then, the anatase phase transforms irreversibly to the rutile phase at $600{ }^{\circ} \mathrm{C}$. This phase transformation is sometimes referred to as ART $[25,26]$. In our study, the rutile $\mathrm{TiO}_{2}$ phase was directly obtained at elevated temperatures. Chou et al. [27] have demonstrated that the kinetics of the anatase to rutile transformation is affected strongly by the $\mathrm{O}$ defect levels because $\mathrm{O}$ vacancies facilitate the rutile transformation. Reidy et al. [28] have shown that $\mathrm{O}$ vacancies provide a low-energy mass transport route and decrease the ART temperature. Thus, high O vacancies result in low ART temperatures. Batzill [29] and Ihara et al. [30] have found that $\mathrm{N}$ doping promotes the rutile transition. In this study, the produced oxide via the annealing of nitride may contain a high level of $\mathrm{O}$ vacancies and lead to a direct rutile transition [31]. The formed tetragonal phase at temperatures above $600{ }^{\circ} \mathrm{C}$ was very similar to the $\mathrm{ZrSiO}_{4}$ phase $(a=0.6604 \mathrm{~nm}, c=0.5979$, space group $=\mathrm{I} 41 / \mathrm{amd})$. However, no Si signal was detected from the ESCA (not shown). Huang et al. [32] have determined that the sputtered $\mathrm{AlCoCrCu}{ }_{0.5} \mathrm{NiFe}$ oxide coatings are in the tetragonal $\mathrm{HCP}$ solid solution phase because the large mixing entropy at elevated temperatures can stabilize solid solutions in multiprincipal elements. Therefore, the formation of a BCT I41/amd solid solution phase via the CrTaTiVZr oxide coating was relevant to the high entropy effect.

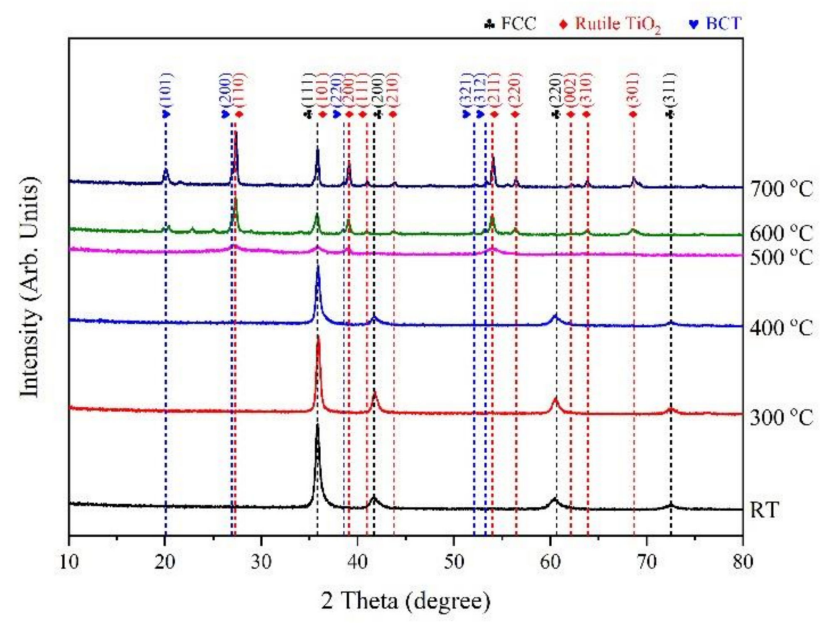

Figure 2. X-ray diffraction patterns of (CrTaTiVZr)N coatings after annealing at different temperatures in air.

Figure 3 shows the SEM micrographs of (CrTaTiVZr)N coatings after annealing at different temperatures in air. The as-deposited typical columnar structure exhibited a cauliflower-like surface feature. No significant change was observed at $300^{\circ} \mathrm{C}$. However, a very thin and dense oxide layer formed at $400{ }^{\circ} \mathrm{C}$ with a thickness of $80 \mathrm{~nm}$ on the surface of the nitride. The oxide layer thickened and revealed a nanopore feature when the annealing temperature was increased to $500^{\circ} \mathrm{C}$. The oxide reaction became rapid and nonuniform at $500{ }^{\circ} \mathrm{C}$. The oxide layer thickness ranged from $500 \mathrm{~nm}$ to $900 \mathrm{~nm}$. At annealing temperature above $600{ }^{\circ} \mathrm{C}$, the coating was fully oxidized and displayed a granular porous structure. 

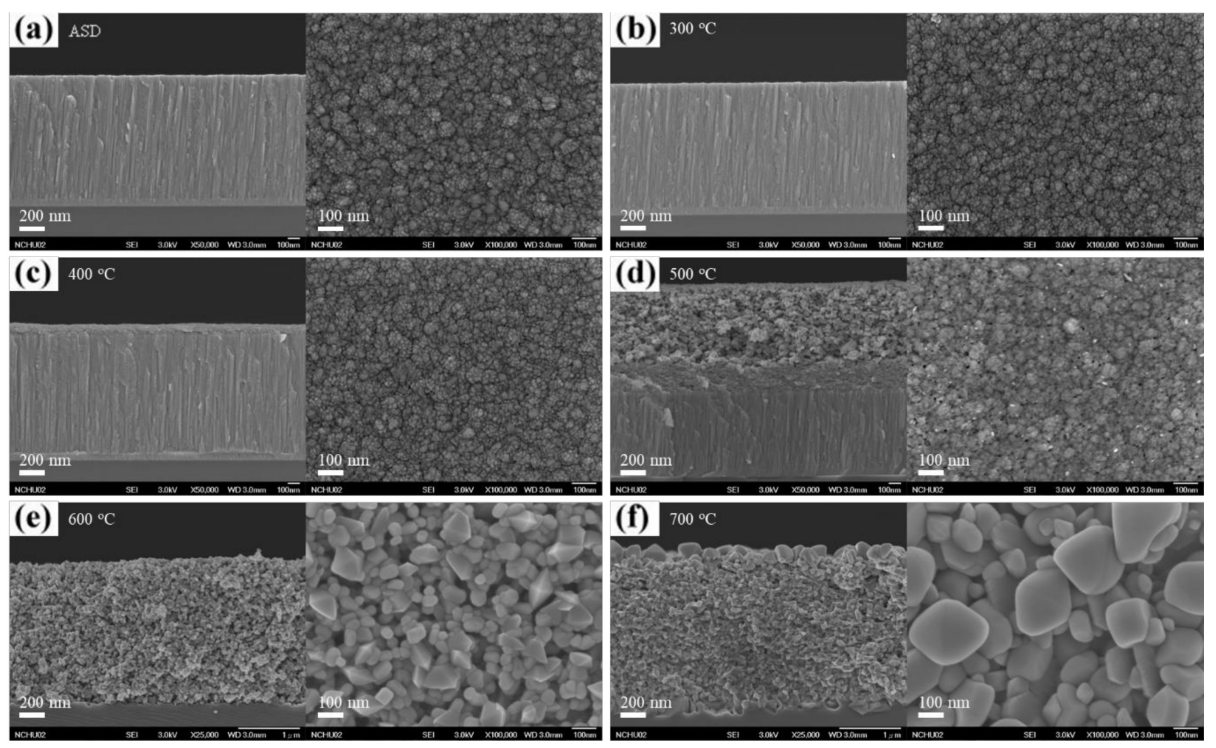

Figure 3. Plan-view and cross-sectional SEM micrographs of the (CrTaTiVZr)N coatings after annealing at different temperatures in air. (a) as-deposited, (b) $300{ }^{\circ} \mathrm{C},(\mathbf{c}) 400{ }^{\circ} \mathrm{C}$, (d) $500{ }^{\circ} \mathrm{C},(\mathbf{e}) 600{ }^{\circ} \mathrm{C},(\mathbf{f}) 700{ }^{\circ} \mathrm{C}$.

TEM was further used to clarify the oxidation behaviors of (CrTaTiVZr)N coatings (Figures 4-7). Similar to the SEM observation, TEM showed that the as-deposited (CrTaTiVZr)N coating exhibited a very dense and compact columnar structure (Figure 4a). The selected area diffraction (SAD) patterns (Figure $4 \mathrm{~b}, \mathrm{c}$ ) of the CrTaTiVZr and the (CrTaTiVZr)N layers demonstrated amorphous and FCC phases, respectively. The combined high-resolution TEM (HRTEM) lattice images (Figure 4d) clearly demonstrated that the nitride layer had high FCC crystallinity. Annealing the coating at $400{ }^{\circ} \mathrm{C}$ resulted in the formation of a thin amorphous oxide with a thickness of around $80 \mathrm{~nm}$ on the nitride coating (Figure $5 a, b)$. The oxide layer contained numerous visible pores with a diameter of 5-30 nm and developed large cracks that were probably due to the $\mathrm{N}$ release and volume expansion during oxidation. The SAD and HRTEM results (Figure $5 b, c$ ) revealed the existence of some unoxidized nitride crystallites in the oxide layer, which indicated that the oxidation behavior of coatings was controlled by diffusion [33]. After annealing at $500{ }^{\circ} \mathrm{C}$, severe oxidation occurred, and the porous oxide layer thickened rapidly (Figure 6a). The microstructures of the surface and the inner oxide layers were significantly different. On the basis of the SAD and the nanobeam diffraction (NBD) patterns (Figure $6 b, c$ ), the phase structure in the inner oxide layer remained unchanged. However, the surface amorphous oxide layer further transformed into the rutile $\mathrm{TiO}_{2}$ crystalline phase. The HRTEM image (Figure 6d) also clarified that the amorphous phase transformed into the rutile $\mathrm{TiO}_{2}$ phase. The TEM observations demonstrated that the formed oxide layer annealed at $500{ }^{\circ} \mathrm{C}$ in air contained rutile $\mathrm{TiO}_{2}$ and amorphous phases. This finding indicated the preferred crystallization of $\mathrm{TiO}_{2}$ in this work. Notably, the behavior of the complex multicomponent (CrTaTiVZr)N alloy was difficult to examine because the alloy contained elements characterized by different oxidation mechanisms. Hence, the tendency toward selective oxidation can be anticipated from the difference in free energy for oxidation per mole of $\mathrm{O}_{2}$. The values are listed in Table 1 [24]. The extent to which this phenomenon happens or the sensitivity of selective oxidation to the difference in thermodynamic stability is assumed to be high. According to Table 1, the high thermodynamic driving forces in $\mathrm{TiO}_{2}$ and $\mathrm{ZrO}_{2}$ results in the predominant formation of $\mathrm{TiO}_{2}$ and $\mathrm{ZrO}_{2}$. However, the phase presentation strongly depends on the crystallization temperature of amorphous materials. Tominaga et al. [34] have determined that the crystallization temperatures are 445,740 , and $480{ }^{\circ} \mathrm{C}$ for $\mathrm{Cr}_{2} \mathrm{O}_{3}, \mathrm{Ta}_{2} \mathrm{O}_{5}$, and $\mathrm{TiO}_{2}$, respectively. Abadias et al. [22] have confirmed that crystalline oxide phases are detected in $\mathrm{ZrN}$, TiN, and TaN after annealing at 500, 550, and $800^{\circ} \mathrm{C}$, respectively. Zou et al. [35] have found that annealing at $500{ }^{\circ} \mathrm{C}$ triggers the crystallization of amorphous $\mathrm{V}_{2} \mathrm{O}_{5}$. Therefore, except $\mathrm{Ta}_{2} \mathrm{O}_{5}$, the binary oxide phase of other target constituents should be observed after annealing at $700{ }^{\circ} \mathrm{C}$. However, the oxidation 
behavior of the multiprincipal elements is very complex. The intense incorporation of elements with different atomic sizes in coatings results in crystallization retardation. Moreover, the ternary oxide phase instead of the individual binary oxide may form during high-temperature oxidation. Müller et al. [36] have reported that TaMoCrTiAl yields the crystal phases of $\mathrm{TiO}_{2}, \mathrm{Al}_{2} \mathrm{O}_{3}, \mathrm{Cr}_{2} \mathrm{O}_{3}$, and $\mathrm{CrTaO}_{4}$ after annealing at $1000{ }^{\circ} \mathrm{C}$. Tsai et al. [37] have oxidized (TiVCrZrHf)N at $600{ }^{\circ} \mathrm{C}$ to form the ( $\mathrm{Zr}, \mathrm{Hf}) \mathrm{TiO}_{4}$ crystal phase. Ren et al. [38] have detected that Ni-based superalloys consists of $\mathrm{Cr}_{2} \mathrm{O}_{3}, \mathrm{TiO}_{2}, \mathrm{NiCr}_{2} \mathrm{O}_{4}, \mathrm{Al}_{2} \mathrm{O}_{3}$, and $\mathrm{CrTaO}_{4}$ crystal phases after annealing at $850{ }^{\circ} \mathrm{C}$. In general, the ternary oxide has higher crystallization temperatures than binary oxide, thereby expanding the amorphous temperature. In oxidized (CrTaTiVZr)N coatings, $\mathrm{TiO}_{2}$ and $\mathrm{ZrO}_{2}$ should be the preferred phases of formation due to their low free energies of formation and low crystallization temperature. However, in this study, the $\mathrm{ZrO}_{2}$ phase was undetected. On the basis of the $\mathrm{ZrO}_{2}-\mathrm{V}_{2} \mathrm{O}_{5}$ phase diagram, $\mathrm{ZrO}_{2}$ and $\mathrm{V}_{2} \mathrm{O}_{5}$ had extremely high affinity and tended to form the $\mathrm{ZrV}_{2} \mathrm{O}_{7}$ phase at relatively low temperatures [39]. Xing et al. [40] have revealed that the phase transition temperature of $\mathrm{ZrV}_{2} \mathrm{O}_{7}$ is $771{ }^{\circ} \mathrm{C}$. Jantschner et al. [41] have discovered that the crystallization of amorphous $\mathrm{ZrV}_{2} \mathrm{O}_{7}$ occurs after annealing above $600{ }^{\circ} \mathrm{C}$. This finding indicates that $\mathrm{V}_{2} \mathrm{O}_{5}$ significantly retards the formation of $\mathrm{ZrO}_{2}$ phase. By contrast, $\mathrm{TiO}_{2}$ and $\mathrm{V}_{2} \mathrm{O}_{5}$ have extremely low mutual solubilities [42,43]. As a result, the rutile $\mathrm{TiO}_{2}$ crystal phase formed preferentially. By further increasing the annealing temperature to $600{ }^{\circ} \mathrm{C}$, the coating achieved complete oxidation and developed a granular porous structure (Figure 7a). The SAD observations (Figure $7 \mathrm{~b}$ ) demonstrated that high temperatures promoted the growth of rutile $\mathrm{TiO}_{2}$ phase and produced a minor BCT solid solution phase. The NBD and the HRTEM images (Figure 7c,d) also verified the growth of a highly rutile $\mathrm{TiO}_{2}$ phase. These results showed that oxidation occurred primarily through the inward diffusion of $\mathrm{O}$. This finding suggested that the formation of oxide phases may have resulted in the escape of $\mathrm{N}$ and large volume expansion during annealing and subsequently led to porosity with many voids. These conditions implied that $\mathrm{O}$ can diffuse freely inward through the voids, intensify oxidation, and adversely affect the coating.

Table 1. Standard free energies of formation of oxides based on the target elements.

\begin{tabular}{cccccc}
\hline Oxide & $\mathrm{Cr}_{2} \mathrm{O}_{3}$ & $\mathrm{Ta}_{2} \mathrm{O}_{5}$ & $\mathrm{TiO}_{2}$ & $\mathrm{~V}_{2} \mathrm{O}_{5}$ & $\mathrm{ZrO}_{2}$ \\
\hline$\Delta \mathrm{G}\left(\mathrm{kJ} \cdot \mathrm{mol}^{-1} \mathrm{O}_{2}\right)$ & 352.7 & 382.2 & 444.4 & 283.86 & 521.4 \\
\hline
\end{tabular}
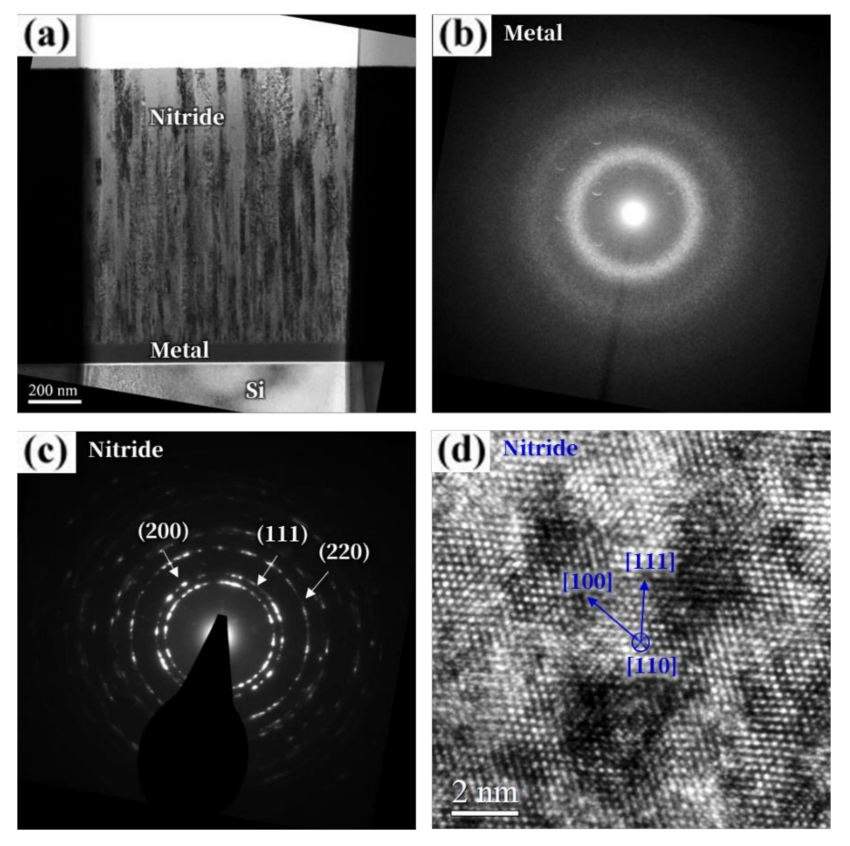

Figure 4. Cross-sectional TEM micrographs of the as-deposited (CrTaTiVZr)N coatings. (a) bright-field image, (b) SAD pattern of the metal interlayer, (c) SAD pattern of nitride layer, (d) HRTEM lattice image. 

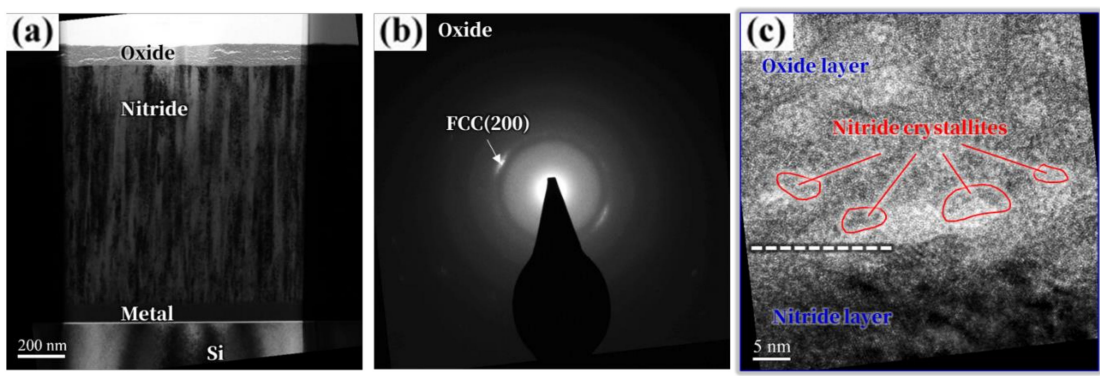

Figure 5. Cross-sectional TEM micrographs of the as-deposited (CrTaTiVZr)N coatings after annealing at $400{ }^{\circ} \mathrm{C}$ in air. (a) bright-field image, (b) SAD pattern of the oxide layer, (c) HRTEM lattice image.
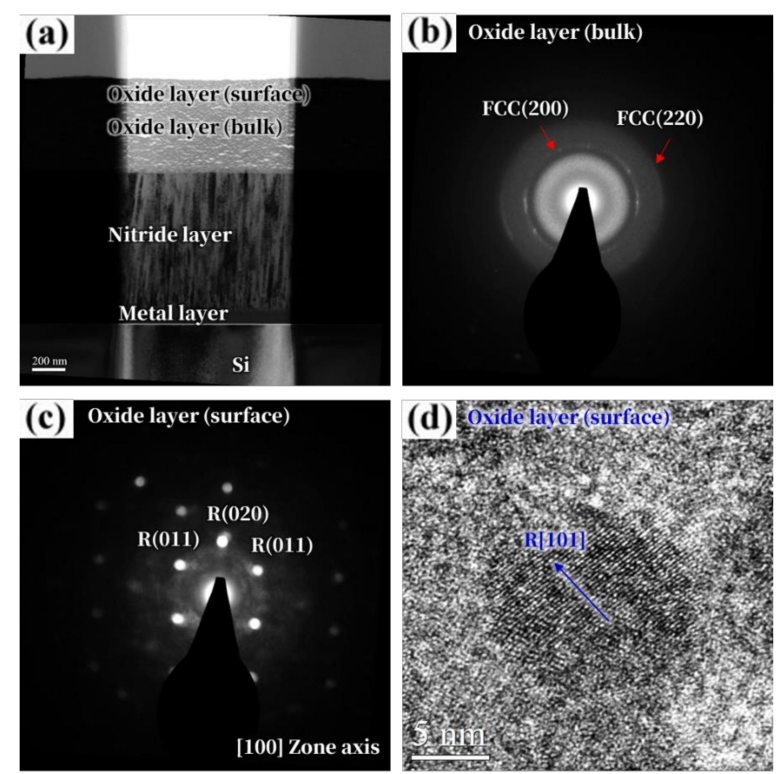

Figure 6. Cross-sectional TEM micrographs of the as-deposited (CrTaTiVZr)N coatings after annealing at $500{ }^{\circ} \mathrm{C}$ in air. (a) bright-field image, (b) SAD pattern of the oxide bulk layer, (c) NBD pattern of the oxide surface layer, (d) HRTEM lattice image.
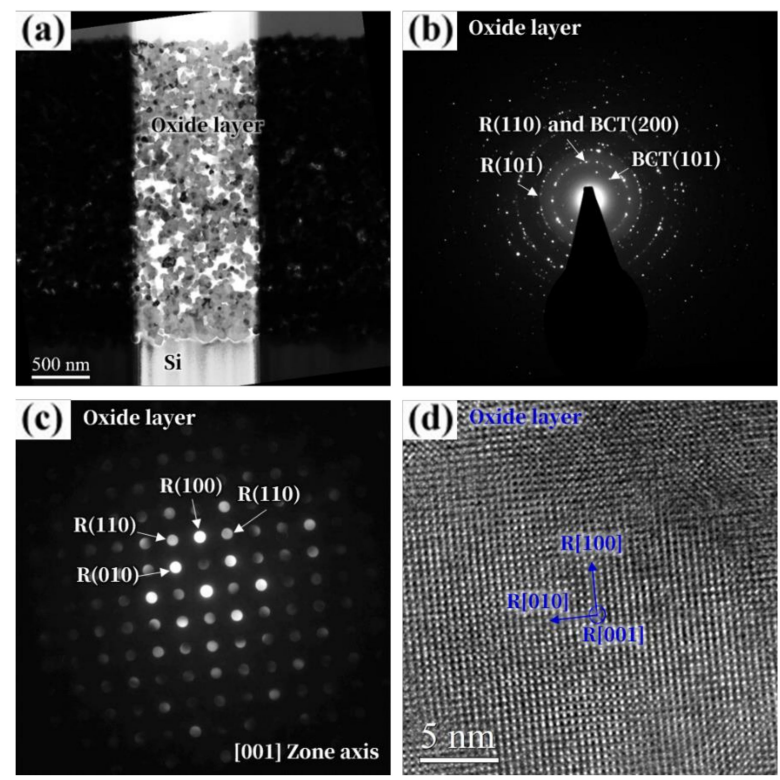

Figure 7. Cross-sectional TEM micrographs of the as-deposited (CrTaTiVZr)N coatings after annealing at $600{ }^{\circ} \mathrm{C}$ in air. (a) bright-field image, (b) SAD pattern of the oxide layer, (c) NBD pattern of the oxide layer, (d) HRTEM lattice image. 
Figure 8 shows the variations in the hardness and elastic modulus of the (CrTaTiVZr)N coatings after annealing at different temperatures in air. The hardness of the as-deposited ( $\mathrm{CrTaTiVZr}) \mathrm{N}$ coatings was about $34.3 \mathrm{GPa}$. Hardness was almost constant during annealing at $300^{\circ} \mathrm{C}$. However, increasing the annealing temperature to $700{ }^{\circ} \mathrm{C}$ significantly reduced the hardness to $1.52 \mathrm{GPa}$.

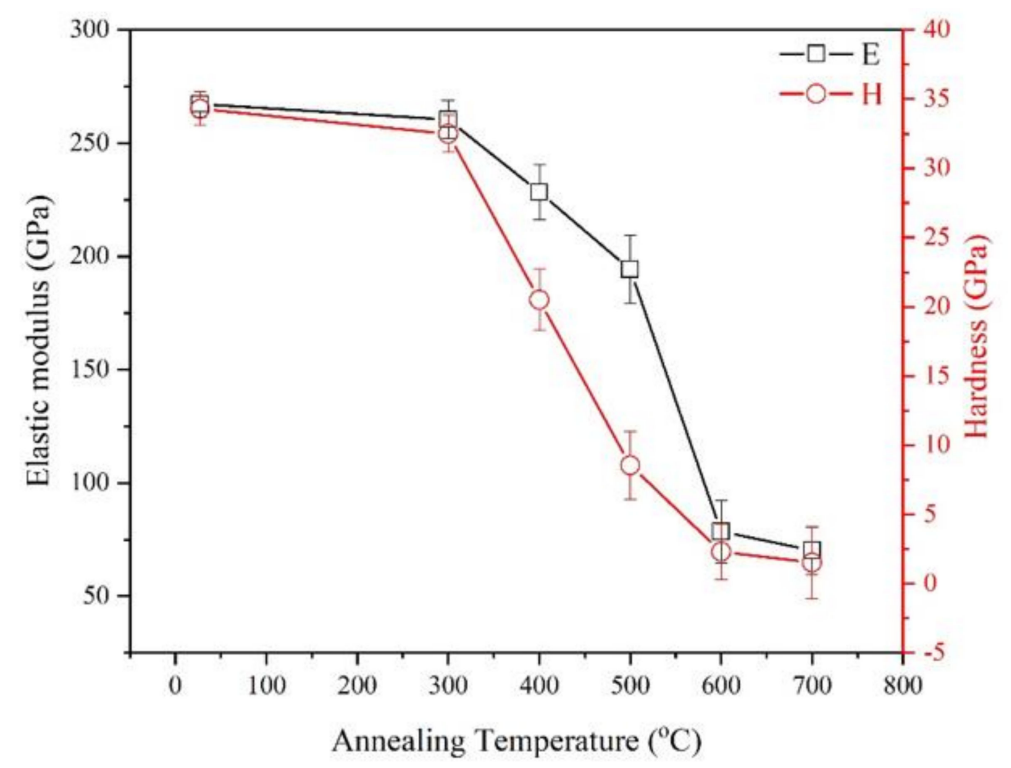

Figure 8. Hardness and elastic modulus of (CrTaTiVZr)N coatings after annealing at different temperatures in air.

The electrical resistivity of coatings also presented a similar trend with annealing temperature, as shown in Figure 9. The electrical resistivity of the as-deposited coatings was $142 \mu \Omega \cdot \mathrm{cm}$ and remained constant when the annealing temperature was increased to $300{ }^{\circ} \mathrm{C}$. Beyond this temperature, the electrical resistivity of the coatings revealed a very sharp reduction from $155 \Omega \cdot \mathrm{cm}$ to $17.5 \Omega \cdot \mathrm{cm}$. Oxides typically yielded smaller hardness and higher electrical resistivity than nitrides. Therefore, poor hardness and electrical conductivity were due to the oxidized coating surface. Moreover, the increased coating porosity at high annealing temperatures considerably decreases hardness and electrical conductivity [44,45].

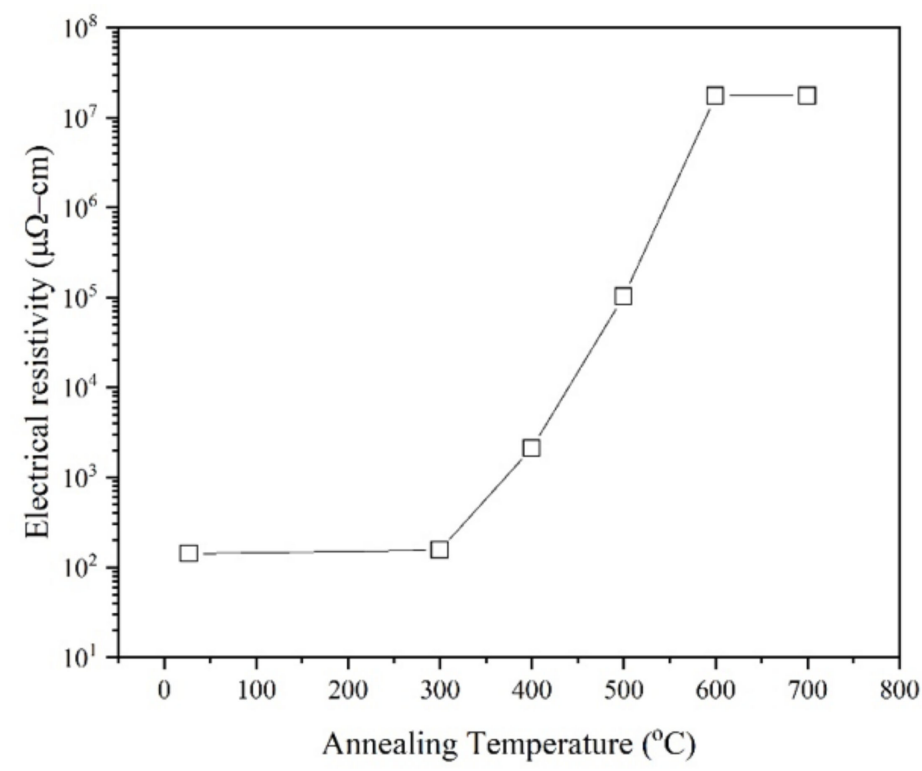

Figure 9. Electrical resistivity of (CrTaTiVZr)N coatings after annealing at different temperatures in air. 


\section{Conclusions}

In this study, (CrTaTiVZr)N coatings were deposited on the Si substrate through the reactive magnetron sputtering process to evaluate their crystal phases, microstructure, and mechanical and electrical properties after oxidation at high temperatures in the air environment. The FCC structure of the as-deposited coating partially changed to amorphous phases on the surface after oxidation at $400{ }^{\circ} \mathrm{C}$ in air for $2 \mathrm{~h}$. The amorphous oxide layer of the coating thickened rapidly along the thickness direction and started to transform into the crystal rutile $\mathrm{TiO}_{2}$ phase near the coating surface. A minor BCT I41/amd solid solution phase appeared at annealing temperatures above $600{ }^{\circ} \mathrm{C}$. The as-deposited coating had a columnar structure, whereas the oxide layer obtained a granular porous structure at temperatures above $500^{\circ} \mathrm{C}$. The average grain size increased with increasing annealing temperature. The mechanical and electrical performance of the oxide layer with porous structure clearly worsened. The hardness and the electrical resistivity of $(\mathrm{CrTaTiVZr}) \mathrm{N}$ coatings decreased to $1.52 \mathrm{GPa}$ and increased to $17.5 \Omega \cdot \mathrm{cm}$, respectively.

Author Contributions: Formal analysis, J.-Y.L.; investigation, J.-Y.L.; data curation, Z.-C.C.; writing—original draft preparation, Z.-C.C.; writing-review and editing, Z.-C.C. All authors have read and agreed to the published version of the manuscript.

Funding: This research was funded by the Ministry of Science and Technology of Taiwan under Grant No. NSC 106-2622-E-167-013-CC3.

Acknowledgments: The present work was supported in part by the Center for Micro/Nano Science and Technology of the National Cheng Kung University.

Conflicts of Interest: The authors declare no conflict of interest.

\section{References}

1. Murty, B.S.; Yeh, J.W.; Ranganathan, S. High-Entropy Alloys; Elsevier Inc.: Amsterdam, The Netherlands, 2014.

2. Gao, M.C.; Yeh, J.W.; Liaw, P.K.; Zhang, Y. High-Entropy Alloys Fundamentals and Applications; Springer International Publishing: Cham, Switzerland, 2016.

3. Miracle, D.B.; Senkov, O.N. A critical review of high entropy alloys and related concepts. Acta Mater. 2017, 122, 448-511. [CrossRef]

4. Kim, Y.S.; Park, H.J.; Lim, K.S.; Hong, S.H.; Kim, K.B. Structural and Mechanical Properties of AlCoCrNi High Entropy Nitride Films: Influence of Process Pressure. Coatings 2020, 10, 10. [CrossRef]

5. Kim, Y.S.; Park, H.J.; Mun, S.C.; Jumaev, E.; Hong, S.H.; Song, G.; Kim, J.T.; Park, Y.K.; Kim, K.S.; Jeong, S.I.; et al. Investigation of structure and mechanical properties of TiZrHfNiCuCo high entropy alloy thin films synthesized by magnetron sputtering. J. Alloys Compd. 2019, 797, 834-841. [CrossRef]

6. Chang, Z.-C.; Tsai, D.-C.; Chen, E.-C. Effect of $\mathrm{N}_{2}$ flow on the structure and mechanical properties of $\left(\right.$ CrTaTiVZr) $N_{x}$ coatings processed by reactive magnetron sputtering. J. Mater. Res. 2015, 30, 924-934. [CrossRef]

7. Chang, Z.-C.; Tsai, D.-C.; Chen, E.-C. Structure and characteristics of reactive magnetron sputtered (CrTaTiVZr)N coatings. Mater. Sci. Semicond. Process. 2015, 39, 30-39. [CrossRef]

8. Pogrebnjak, A.D.; Beresnev, V.M.; Smyrnova, K.V.; Kravchenko, Y.; Zukowski, P.V.; Bondarenko, G.G. The influence of nitrogen pressure on the fabrication of the two-phase superhard nanocomposite (TiZrNbAlYCr)N coatings. Mater. Lett. 2018, 211, 316-318. [CrossRef]

9. Chang, C.H.; Li, P.W.; Wu, Q.Q.; Wang, M.H.; Sung, C.C.; Hsu, C.-Y. Nanostructured and mechanical properties of high-entropy alloy nitride films prepared by magnetron sputtering at different substrate temperatures. Mater. Technol. 2018, 34, 343-349. [CrossRef]

10. Chen, T.K.; Shun, T.T.; Yeh, J.W.; Wong, M.S. Nanostructured nitride films of multi-element high-entropy alloys by reactive DC sputtering. Surf. Coat. Technol. 2004, 188-189, 193-200. [CrossRef]

11. Liu, L.; Zhu, J.B.; Hou, C.; Li, J.C.; Jiang, Q. Dense and smooth amorphous films of multicomponent FeCoNiCuVZrAl high-entropy alloy deposited by direct current magnetron sputtering. Mater. Des. 2013, 46, 675-679. [CrossRef] 
12. Chang, Z.-C. Structure and properties of duodenary (TiVCrZrNbMoHfTaWAlSi)N coatings by reactive magnetron sputtering. Mater. Chem. Phys. 2018, 220, 98-110. [CrossRef]

13. Shu, F.Y.; Liu, S.; Zhao, H.Y.; He, W.X.; Sui, S.H.; Zhang, J.; He, P.; Xu, B.S. Structure and high-temperature property of amorphous composite coating synthesized by laser cladding $\mathrm{FeCrCoNiSiB}$ high-entropy alloy powder. J. Alloys Compd. 2018, 731, 662-666. [CrossRef]

14. Jin, G.; Cai, Z.; Guan, Y.; Cui, X.; Liu, Z.; Li, Y.; Dong, M.; Zhang, D. High temperature wear performance of laser-cladded FeNiCoAlCu high-entropy alloy coating. Appl. Surf. Sci. 2018, 445, 113-122. [CrossRef]

15. Chen, S.; Chen, X.; Wang, L.; Liang, J.; Liu, C. Laser cladding FeCrCoNiTiAl high entropy alloy coatings reinforced with self-generated TiC particles. J. Laser Appl. 2016, 29, 012004. [CrossRef]

16. Yao, C.; Wei, B.; Zhang, P.; Lu, X.; Liu, P.; Tong, Y. Facile preparation and magnetic study of amorphous Tm-Fe-Co-Ni-Mn multicomponent alloy nanofilm. J. Rare Earths 2011, 29, 133-137. [CrossRef]

17. Li, Q.; Yue, T.; Guo, Z. Electro-spark Deposition of Multi-Element High Entropy Alloy Coating; ASM International: Almere, The Netherlands, 2010.

18. Yin, S.; Li, W.; Song, B.; Yan, X.; Kuang, M.; Xu, Y.; Wen, K.; Lupoi, R. Deposition of FeCoNiCrMn high entropy alloy (HEA) coating via cold spraying. J. Mater. Sci. Technol. 2019, 35, 1003-1007. [CrossRef]

19. Popov, V.V.; Katz-Demyanetz, A.; Koptyug, A.; Bamberger, M. Selective electron beam melting of $\mathrm{Al}_{0.5} \mathrm{CrMoNbTa}_{0.5}$ high entropy alloys using elemental powder blend. Heliyon 2019, 5, e01188. [CrossRef]

20. Cai, Z.; Wang, Y.; Cui, X.; Jin, G.; Li, Y.; Liu, Z.; Dong, M. Design and microstructure characterization of FeCoNiAlCu high-entropy alloy coating by plasma cladding: In comparison with thermodynamic calculation. Surf. Coat. Technol. 2017, 330, 163-169. [CrossRef]

21. Tsai, D.-C.; Huang, Y.-L.; Lin, S.-R.; Jung, D.-R.; Chang, S.-Y.; Shieu, F.-S. Structure and mechanical properties of (TiVCr)N coatings prepared by energetic bombardment sputtering with different nitrogen flow ratios. J. Alloys Compd. 2011, 509, 3141-3147. [CrossRef]

22. Abadias, G.; Koutsokeras, L.E.; Siozios, A.; Patsalas, P. Stress, phase stability and oxidation resistance of ternary Ti-Me-N (Me=Zr, Ta) hard coatings. Thin Solid Films 2013, 538, 56-70. [CrossRef]

23. Pierson, H.O. Handbook of Refractory Carbides and Nitrides; Noyes Publications: Westwood, NJ, USA, 1996.

24. Dean, J.A. Lange's Handbook of Chemistry; McGraw-Hill: New York, NY, USA, 1999.

25. Rath, C.; Mohanty, P.; Pandey, A.C.; Mishra, N.C. Oxygen vacancy induced structural phase transformation in $\mathrm{TiO}_{2}$ nanoparticles. J. Phys. D Appl. Phys. 2009, 42, 205101. [CrossRef]

26. Ghosh, T.B.; Dhabal, S.; Datta, A.K. Erratum: On crystalline size dependence of phase stability of nanocrystalline $\mathrm{TiO}_{2}$. Appl. Phys. 94, 4577 (2003). J. Appl. Phys. 2003, 95, 408. [CrossRef]

27. Chou, P.-W.; Wang, Y.-S.; Lin, C.-C.; Chen, Y.-J.; Cheng, C.-L.; Wong, M.-S. Effect of carbon and oxygen on phase transformation of titania films during annealing. Surf. Coat. Technol. 2009, 204, 834-839. [CrossRef]

28. Reidy, D.J.; Holmes, J.D.; Morris, M.A. The critical size mechanism for the anatase to rutile transformation in $\mathrm{TiO}_{2}$ and doped-TiO 2 . J. Eur. Ceram. Soc. 2006, 26, 1527-1534. [CrossRef]

29. Batzill, M.; Morales, E.H.; Diebold, U. Influence of Nitrogen Doping on the Defect Formation and Surface Properties of $\mathrm{TiO}_{2}$ Rutile and Anatase. Phys. Rev. Lett. 2006, 96, 026103. [CrossRef]

30. Ihara, T.; Miyoshi, M.; Iriyama, Y.; Matsumoto, O.; Sugihara, S. Visible-light-active titanium oxide photocatalyst realized by an oxygen-deficient structure and by nitrogen doping. Appl. Catal. B Environ. 2003, 42, 403-409. [CrossRef]

31. Chen, H.-Y.; Lu, F.-H. Oxidation behavior of titanium nitride films. J. Vac. Sci. Technol. A 2005, 23, $1006-1009$. [CrossRef]

32. Huang, Y.-S.; Chen, L.; Lui, H.-W.; Cai, M.-H.; Yeh, J.-W. Microstructure, hardness, resistivity and thermal stability of sputtered oxide films of $\mathrm{AlCoCrCu}_{0.5} \mathrm{NiFe}$ high-entropy alloy. Mater. Sci. Eng. A 2007, 457, 77-83. [CrossRef]

33. Unutulmazsoy, Y.; Merkle, R.; Fischer, D.; Mannhart, J.; Maier, J. The oxidation kinetics of thin nickel films between 250 and $500{ }^{\circ} \mathrm{C}$. Phys. Chem. Chem. Phys. 2017, 19, 9045-9052. [CrossRef]

34. Tominaga, K.; Adachi, H.; Wasa, K. 6-Functional Thin Films. In Handbook of Sputtering Technology, 2nd ed.; Wasa, K., Kanno, I., Kotera, H., Eds.; William Andrew Publishing: Oxford, UK, 2012; p. 495. ISBN 978-1-4377-3483-6.

35. Zou, C.W.; Yan, X.D.; Patterson, D.; Emanuelsson, E.A.C.; Bian, J.M.; Gao, W. Temperature sensitive crystallization of V2O5: From amorphous film to $\beta$-V2O5nanorods. CrystEngComm 2010, 12, 691-693. [CrossRef] 
36. Müller, F.; Gorr, B.; Christ, H.-J.; Müller, J.; Butz, B.; Chen, H.; Kauffmann, A.; Heilmaier, M. On the oxidation mechanism of refractory high entropy alloys. Corros. Sci. 2019, 159, 108161. [CrossRef]

37. Tsai, D.-C.; Chang, Z.-C.; Kuo, L.-Y.; Lin, T.-J.; Lin, T.-N.; Shiao, M.-H.; Shieu, F.-S. Oxidation resistance and structural evolution of (TiVCrZrHf)N coatings. Thin Solid Films 2013, 544, 580-587. [CrossRef]

38. Ren, W.; Ouyang, F.; Ding, B.; Zhong, Y.; Yu, J.; Ren, Z.; Zhou, L. The influence of CrTaO4 layer on the oxidation behavior of a directionally-solidified nickel-based superalloy at 850-900 ${ }^{\circ} \mathrm{C}$. J. Alloys Compd. 2017, 724, 565-574. [CrossRef]

39. Ondik, H.; McMurdie, H.F. Phase Diagrams for Zirconium and Zirconia Systems; American Ceramic Society: Columbus, DC, USA, 2017.

40. Xing, X.; Zhu, Z.; Qiu, X.; Liu, G. Zero-Thermal Expansion and Heat Capacity of Zirconium Pyrovanadate Doped with Zirconia and Vanadium (V) Oxide. Rare Met. 2001, 20, 1-4.

41. Jantschner, O. Investigation on Vanadium Containing Zirconia Coatings for High Temperature Sliding Interfaces; University of Leoben: Leoben, Austria, 2011.

42. Habel, D.; Stelzer, J.B.; Feike, E.; Schröder, C.; Hösch, A.; Hess, C.; Knop-Gericke, A.; Caro, J.; Schubert, H. Phase development in the catalytic system V2O5/TiO2 under oxidising conditions. J. Eur. Ceram. Soc. 2006, 26, 3287-3294. [CrossRef]

43. Malan, W.D.; Akdogan, G.; Taskinen, P.; Hamuyuni, J.; Zietsman, J. Phase equilibria and thermodynamic evaluation of the Ti-V-O system in air. Calphad 2018, 63, 220-228. [CrossRef]

44. Tsai, D.-C.; Chang, Z.-C.; Kuo, B.-H.; Tsao, C.-T.; Chen, E.-C.; Shieu, F.-S. Influence of discharge power on the structural, electro-optical, and mechanical properties of (TiZrHf)N coatings. J. Alloys Compd. 2015, 622, 446-457. [CrossRef]

45. Tsai, D.-C.; Chang, Z.-C.; Kuo, B.-H.; Chen, B.-C.; Chen, E.-C.; Shieu, F.-S. Wide variation in the structure and physical properties of reactively sputtered (TiZrHf)N coatings under different working pressures. J. Alloys Compd. 2018, 750, 350-359. [CrossRef]

(C) 2020 by the authors. Licensee MDPI, Basel, Switzerland. This article is an open access article distributed under the terms and conditions of the Creative Commons Attribution (CC BY) license (http://creativecommons.org/licenses/by/4.0/). 